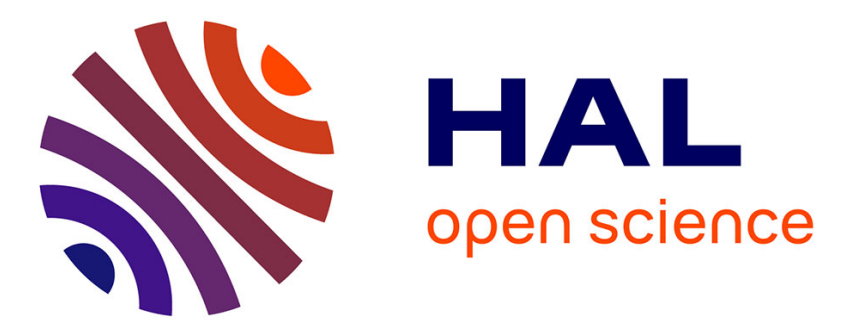

\title{
Visualization of peripheral pulmonary artery stenosis using high-resolution multidetector computed tomography
}

Gf Greil, A Kuettner, M Schoebinger, H-P Meinzer, Cd Claussen, M Hofbeck, L Sieverding

\section{To cite this version:}

Gf Greil, A Kuettner, M Schoebinger, H-P Meinzer, Cd Claussen, et al.. Visualization of peripheral pulmonary artery stenosis using high-resolution multidetector computed tomography. Vascular Medicine, 2005, 10 (3), pp.235-236. 10.1191/1358863x05vm613xx . hal-00572126

\section{HAL Id: hal-00572126 \\ https://hal.science/hal-00572126}

Submitted on 1 Mar 2011

HAL is a multi-disciplinary open access archive for the deposit and dissemination of scientific research documents, whether they are published or not. The documents may come from teaching and research institutions in France or abroad, or from public or private research centers.
L'archive ouverte pluridisciplinaire HAL, est destinée au dépôt et à la diffusion de documents scientifiques de niveau recherche, publiés ou non, émanant des établissements d'enseignement et de recherche français ou étrangers, des laboratoires publics ou privés. 


\title{
Images in vascular medicine
}

\section{Visualization of peripheral pulmonary artery stenosis using high-resolution multidetector computed tomography}

\author{
GF Greila , A Kuettnerb, M Schoebingerc, H-P Meinzerc, CD Claussen ${ }^{b}$, M Hofbeck ${ }^{a}$ and L Sieverdinga
}

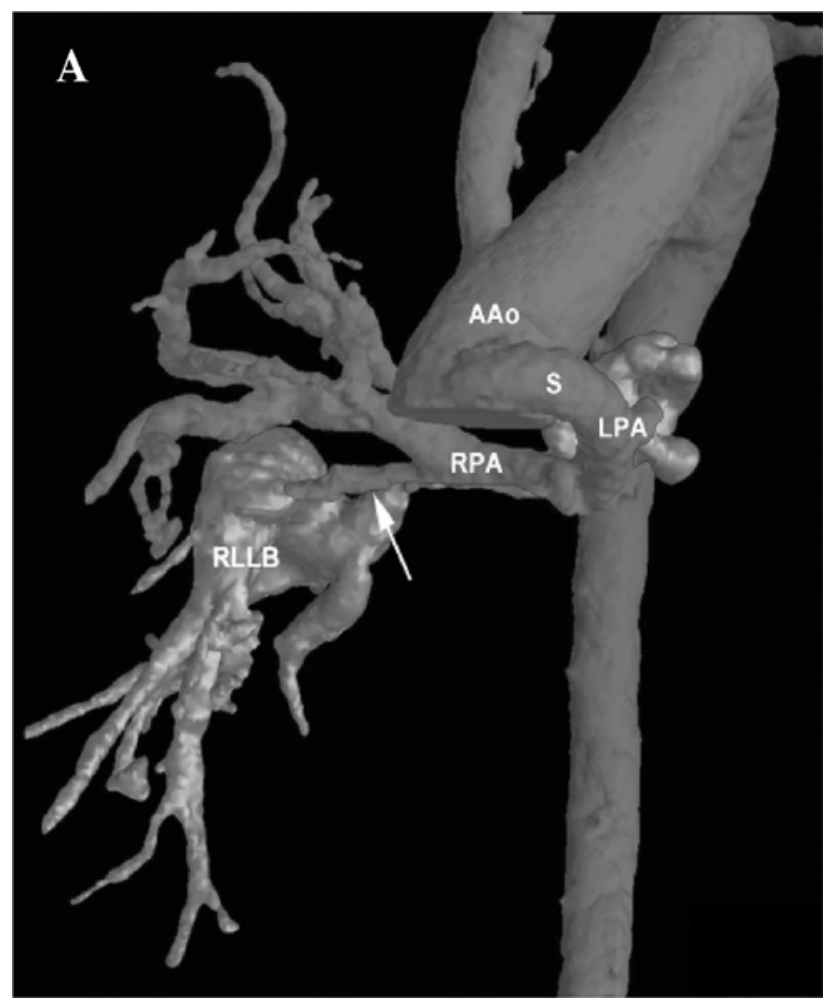

Panel A

A 3-year and 9-month-old patient $(7.1 \mathrm{~kg})$ with pulmonary atresia, ventricular septal defect and multifocal lung perfusion with major aorto-pulmonary collateral arteries (MAPCA) had shunt implantation connecting the hypoplastic central pulmonary arteries

aDepartment of Pediatric Cardiology, University of Tuebingen, Germany; 'bepartment of Radiology, University of Tuebingen, Germany; 'Division of Medical and Biological Informatics, German Cancer Research Center, Heidelberg, Germany

Address for correspondence: Gerald F Greil, Department of Pediatric Cardiology, Children's Hospital, University of Tuebingen, Hoppe-Seyler-Strasse 1, 72076 Tuebingen, Germany. Tel: +497071 2987147; Fax: +497071 295127; E-mail: gerald.greil@med.uni-tuebingen.de

Video footage of this can be seen at http://www.vascularmed journal.com by clicking on the 'Additional material' button.

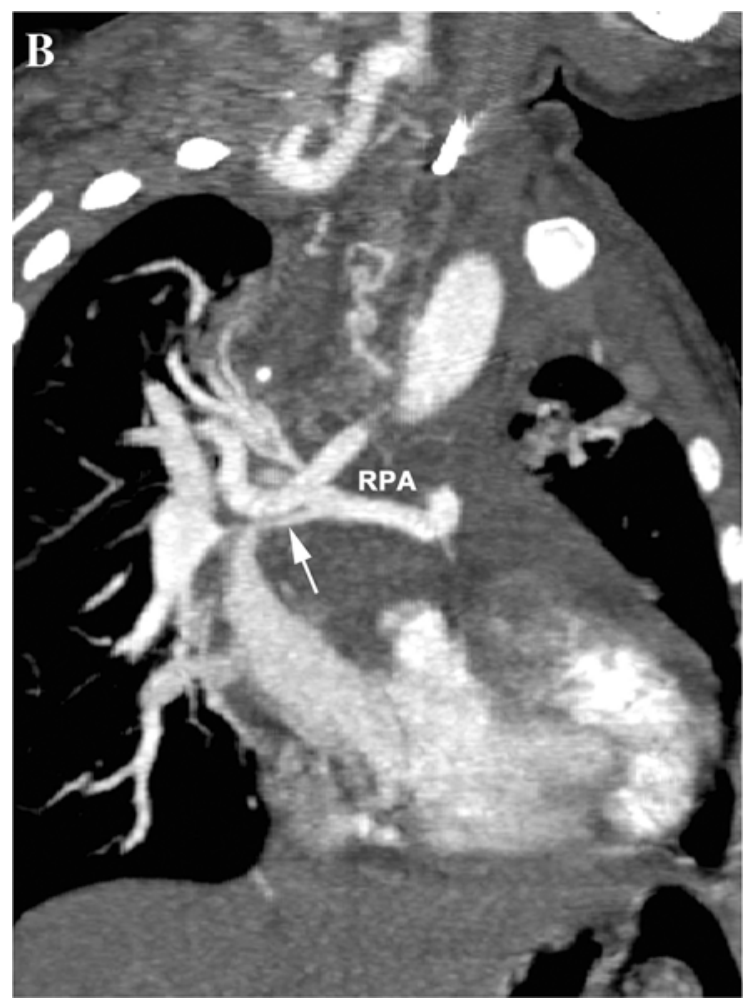

Panel B

to the aorta (Panel $A ; S=$ Shunt, $A A o=$ ascending aorta, $\mathrm{RPA}=$ right pulmonary artery, $\mathrm{LPA}=$ left pulmonary artery, RLLB = right lower lung branch). Postoperatively the right upper lung was hyperperfused due to MAPCA, which was occluded interventionally in the catheterization laboratory. Unfortunately the patient could not be weaned off the ventilator due to persistent hyperperfusion of the right upper lung and hypoperfusion of the right lower lung.

The arterial and venous vascular system was visualized with multidetector computed tomography (MDCT, Panels $A$ and $B$ ). After venous injection of $17 \mathrm{ml}$ of contrast agent (Imeron 400) the neck, thorax and the upper abdomen were imaged within 10 seconds with nearly isotropic voxels (Somatom Sensation, 16 detectors, collimation $0.75 \mathrm{~mm}, 80 \mathrm{kV}, 98 \mathrm{eff}$. mAs, voxelsize $0.5 \times 0.5 \times 0.6 \mathrm{~mm}^{3}$ ). A stenotic vessel (Panels $A-D$, arrow) to the right lower lung was detected in the maximal intensity projection image (Panel $B$ ) and the surface rendered model (Panel A). Catheterization was performed confirming the MDCT results (Panel $\mathrm{C}$ ). The stenosis was balloon dilated successfully (Panel D, arrow). 


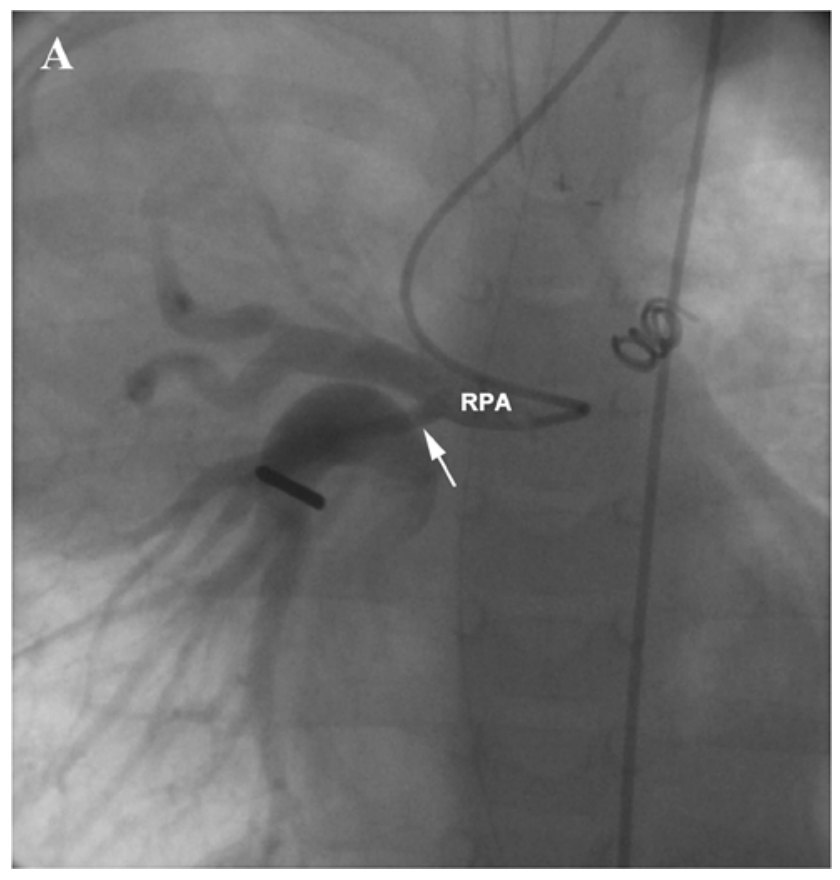

Panel C

Perfusion of the right lung improved and the patient could be weaned off the ventilator.

Precise knowledge of the pulmonary vasculature is the basis for adequate treatment of patients with pulmonary atresia and ventricular septal defect. ${ }^{1,2}$ So far MAPCA have been visualized by selective injections of contrast agents in the catheterization laboratory. ${ }^{2,3}$ With MDCT submillimetre high-resolution images with nearly isotropic voxels can be obtained. MDCT has the potential for visualization of the pulmonary vascular tree in complex congenital heart disease in children.

Movie 1A A 360-degree spin of the 3D surface rendered model shows anatomical structures as indicated in Panel $A$. The ascending aorta (AAo), the aortopulmonary shunt (S), the right pulmonary artery (RPA) with the right upper and middle pulmonary lobe and the left pulmonary artery (LPA) are coloured red. The stenotic segment from the right pulmonary artery to the right lower pulmonary lobe (arrow) is also coloured red. The right lower lung branch (RLLB) is coloured blue.

Movie 2A Selective injection of contrast agent in the right pulmonary artery (RPA) showing the stenotic right lower lung branch (arrow) before balloon dilation.

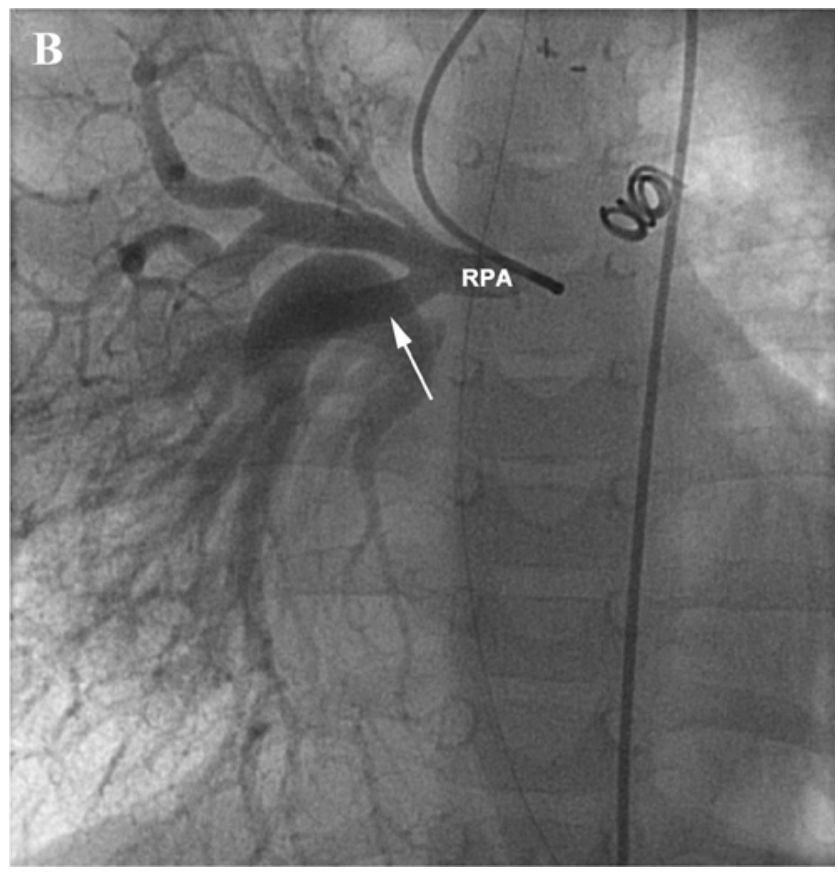

Panel D

Movie 2B Selective injection of contrast agent in the right pulmonary artery (RPA) showing the increased diameter of the right lower lung branch (arrow) after balloon dilation.

\section{References}

1 Van Praagh R, Ando M, Van Praagh S et al. Pulmonary atresia: anatomic considerations. In: Langford BS, Rowe RD eds. The child with congenital heart disease after surgery. Mount Kisco, NY: Futura, 1976: 103-41.

2 O'Leary PW, Mair DD, Edwards WD, Julsrud PR, Puga FJ, Goldmuntz E. Pulmonary atresia and ventricular septal defect. In: Allen HD, Clark EB, Gutgesell HP, Driscoll DJ eds. Heart disease in infants, children and adolescents. Philadelphia, PA: Lippincott Williams \& Wilkins, 2001: 864-79.

3 Geva T, Greil GF, Marshall AC, Landzberg M, Powell AJ. Gadolinium-enhanced 3-dimensional magnetic resonance angiography of pulmonary blood supply in patients with complex pulmonary stenosis or atresia: comparison with x-ray angiography. Circulation 2002; 106: 473-78. 